ANUARIO DE ESTUdIOS MEDIEVALES

48/1, enero-junio de 2018, pp. 81-115

ISSN 0066-5061

https://doi.org/10.3989/aem.2018.48.1.03

\title{
HERMANAS DESIGUALES. LAS JERARQUÍAS URBANAS A TRAVÉS DE LAS HERMANDADES BAJOMEDIEVALES*
}

\author{
UNEQUAL SISTERS. URBAN HIERARCHIES \\ IN LATE MEDIEVAL CASTILIAN HERMANDADES
}

\author{
MARÍA ÁNGELES MARTÍN ROMERA \\ Ludwig-Maximilians-Universität München \\ http://orcid.org/0000-0002-0079-8257
}

\begin{abstract}
Resumen: Este artículo es una propuesta de análisis de la jerarquización urbana a través de la perspectiva de las propias ciudades, atendiendo a sus políticas de asociación y a su sistema interno de reconocimiento de jerarquías. Con este objetivo se analiza el fenómeno de las hermandades castellanas desde su aparición en el siglo XIII hasta el reinado de Enrique IV atendiendo tanto a las redes urbanas que reflejan, como al creciente proceso de jerarquización interna sancionado por la progresiva regulación de estas instituciones. La conclusión es que las hermandades actúan a la vez como síntoma y causa de la jerarquización urbana en el territorio hispánico y, por ello, constituyen un ámbito privilegiado para el estudio de este fenómeno.
\end{abstract}

Palabras clave: hermandades; Castilla; jerarquización urbana; ciudades; ligas urbanas; redes urbanas.

Abstract: The present article offers a different approach to urban hierarchies by focusing on the cities' own perspective on the subject, targeting their political associations and their internal system of hierarchical recognition. With that purpose, it studies the phenomenon of Castilian Hermandades (urban leagues or alliances) from their birth in the $13^{\text {th }}$ century to the reign of Henry IV. In particular, it analyses the urban networks that these leagues mirrored and their process of increasing internal hierarchical distinction, sanctioned by the multiplying regulations of these institutions. The main conclusion is that the Hermandades were at the same time symptom and cause of the developing urban hierarchies in the Hispanic area and, therefore, they are a prime setting for the study of this phenomenon.

Keywords: hermandades; Castile; urban hierarchy; cities; urban leagues; urban networks.

\section{SUMARIO}

1. Introducción.- 2. Las hermandades como contexto de jerarquización urbana.3. Las jerarquías interurbanas en las hermandades entre los siglos XIII-XV.-3.1. Los precedentes.-3.2. El periodo clásico de las hermandades (1282-1325).- 3.3. La Hermandad vieja de Toledo, Talavera y Ciudad Real.- 3.4. Las hermandades en época de Enrique IV.- 4. Conclusiones.- 5. Bibliografía citada.

\footnotetext{
* Este trabajo se inserta en el proyecto de Investigación del Ministerio de Economía y Competitividad: "La jerarquización urbana: villas y ciudades en Castilla (1450-1561)" (HAR2013-44014-P).

Cómo citar este artículo: Martín Romera, María Ángeles (2018), Hermanas desiguales. Las jerarquías urbanas a través de las hermandades bajomedievales, "Anuario de Estudios Medievales" 48/1, pp. 81-115. https://doi.org/10.3989/ aem.2018.48.1.03

Copyright: (C) 2018 CSIC. Este es un artículo de acceso abierto distribuido bajo los términos de la licencia de uso y distribución Creative Commons Reconocimiento 4.0 Internacional (CC BY 4.0).
} 


\title{
1. INTRODUCCIÓN ${ }^{1}$
}

Uno de los autores que mejor conoce el movimiento hermandino y que más ha publicado al respecto, César González Mínguez, escribía en 2006:

\begin{abstract}
Desde el punto de vista de la historia del poder, el estudio de las hermandades concejiles puede hacerse utilizando una doble perspectiva, es decir, la de las relaciones que mantienen con el poder regio, lo que sería una proyección hacia afuera, y la de las relaciones que guardan con los grupos oligárquicos que controlan el poder concejil, o sea, una proyección hacia el interior de la estructura de poder concejil ${ }^{2}$.
\end{abstract}

Esta frase resume perfectamente dos de las perspectivas que más ampliamente -y con razón, pues no en vano resultan fundamentales para la comprensión de este fenómeno-, se han desarrollado al tratar la cuestión de las hermandades. Sin embargo, evidencia también una carencia en la historiografía al respecto, ya que el afán por analizar las relaciones con el poder regio y con las oligarquías concejiles ha llevado a descuidar las relaciones que se establecieron entre las distintas ciudades en el marco de estas asociaciones. Quizás por tratarse de un tema implícito en el propio concepto de hermandad o, más probablemente, por la falta de documentación directamente derivada de las negociaciones entre las ciudades, - en especial para las hermandades del periodo clásico (1282-1325)-, de las muchas páginas dedicadas a este tema, pocas se han detenido a analizar en qué medida estas ligas interurbanas afectaron, determinaron o reprodujeron las redes de relaciones existentes entre los centros urbanos de los reinos hispánicos.

La relación de las hermandades con el devenir histórico del conjunto del reino, en particular las luchas entre la monarquía y la nobleza y los intentos centralizadores de la corona, ha sido sobradamente discutida por la historiografía. En las últimas décadas, a pesar de que distintos autores, como Charles Tilly, han insistido en que las redes urbanas fueron elementos clave en la construcción de los Estados modernos ${ }^{3}$ y aunque diversos historiadores castellanos han destacado la contribución de las mismas a la gobernabilidad del reino ${ }^{4}$, el protagonismo historiográfico de los orígenes del Estado ha subrayado pre-

\footnotetext{
${ }^{1}$ Abreviaturas utilizadas: $\mathrm{AMN}=$ Archivo Municipal de Nájera; $\mathrm{AML}=$ Archivo Municipal de León; ADMS = Archivo Ducal de Medina Sidonia; BNM = Biblioteca Nacional de Madrid; AMV, Actas = Archivo Municipal de Valladolid, Actas Concejiles .

${ }^{2}$ González 2006, pp. 17-18.

${ }^{3}$ Tilly 1994, p. 6.

${ }^{4}$ Asenjo 2008.
} 
ferentemente la perspectiva corona-ciudades ${ }^{5}$. El resultado es que, a pesar de que pocos fenómenos medievales urbanos han merecido la atención que la historiografía ha dedicado a las hermandades ${ }^{6}$, existe una llamativa ausencia de estudios que analicen el impacto de estas en la jerarquización urbana.

Las hermandades como vehículo propio y autónomo de las ciudades para coaligarse, comunicarse y tomar decisiones conjuntamente, son un ámbito privilegiado para el estudio de un tipo de jerarquización urbana que, en teoría, respondía primordialmente a criterios urbanos y se dirimía en función de las cuestiones que interesaban y preocupaban a las ciudades. En este sentido existirían grandes diferencias dependiendo de las distintas tipologías de hermandad, pues como es sabido no fueron iguales las hermandades generales que las mayores, las menores o las de tipo económico como la Hermandad Vieja de Toledo o de la Marina de Castilla ${ }^{7}$. Dichas distinciones, sin ser superfluas, no afectan al propósito de este artículo, porque todas estas hermandades coinciden en reproducir, reforzar y renegociar un sistema jerárquico entre sus miembros y ayudan a reconstruir una determinada regionalización del territorio. José María Mínguez Fernández, a colación de esta diversidad entre las hermandades señalaba que a pesar de las diferencias cualitativas:

unas y otras tienen en común que son instituciones que emanan de una decisión autónoma de los concejos integrantes de la Hermandad al margen de condicionamientos procedentes de cualquier instancia política superior. Son, en definitiva, resultado de la autonomía política de los concejos que se inscribe en la parcelación o fragmentación de la soberanía característica de la estructura política del feudalismo tal como se ha ido constituyendo y consolidando a lo largo del proceso repoblador ${ }^{8}$.

Si bien esta autonomía e independencia de las ciudades a menudo es tan virtual como la supuesta igualdad entre localidades hermanas, el exhaustivo estudio de la influencia de elementos como la nobleza, la monarquía o las cortes realizado por autores previos justifica que en este artículo se relegue el análisis de dichas intromisiones a un segundo plano ${ }^{9}$. En su lugar se provee una perspectiva diferente, que se centra en cómo estas ligas urbanas gestionaron

\footnotetext{
${ }^{5}$ Casado 1987; Rucquoi 1987; Asenjo 2005.

${ }^{6}$ Desde los trabajos clásicos del siglo XIX (Paz 1987; Häbler 1885, 1886) y la obra de Puyol 1913 , numerosos han sido los estudios centrados en el tema. Se destacan aquí tan solo algunos de los títulos más significativos: Suárez 1951; Bermejo 1988; Mínguez 1990; González 1992; Asenjo 1997; Fuentes 2008. p. 546 .

7 Una propuesta de clasificación puede verse en Suárez 1951, p. 7; o en Mínguez 1990,

${ }^{8}$ Mínguez 1990, p. 546.

${ }^{9}$ Acerca de las relaciones entre las hermandades y las cortes véase Fuentes 2008.
} 
las relaciones entre los propios concejos hermanados y con las áreas bajo su jurisdicción, negociando y disputando la influencia y liderazgo sobre las distintas redes urbanas y sobre el territorio.

Con este objetivo, en primer lugar, se propone un modelo de análisis de la jerarquización del territorio a través de las ligas urbanas. Modelo diferente y complementario a aquellos que tienden a centrarse en redes eminentemente económicas. En segundo lugar, se realiza un recorrido histórico por los movimientos hermandinos desde sus inicios hasta el final del reinado de Enrique IV, exponiendo cómo las hermandades reprodujeron o reforzaron la jerarquización interurbana en un difícil equilibrio entre la teórica igualdad entre los entes hermanados y la desigualdad existente en la práctica, desigualdad que será progresivamente sancionada por las propias regulaciones de estas instituciones.

\section{LAS HERMANDADES COMO CONTEXTO DE JERARQUIZACIÓN URBANA}

A pesar de que el concepto de hermandad parte de un sentido igualitario, de alianza entre pares con las mismas obligaciones, paradójicamente, las hermandades constituidas entre ciudades en época medieval son al mismo tiempo un ámbito preferente para la gestación, discusión, refuerzo y sanción de las jerarquías interurbanas. Toda interacción (económica o política) entre diferentes núcleos urbanos conlleva una negociación en la que se ponen en juego de forma más o menos explícita un conjunto de fuerzas efectivas o atribuidas $y$, por consiguiente, una autoridad o preeminencia real o percibida, que afectan necesariamente a las comunicaciones, plasmando asimetrías dentro de unas relaciones que en su base teórica habían de ser simétricas.

La jerarquización urbana ha sido entendida prevalentemente en clave económica, fuertemente dependientes de los flujos mercantiles ${ }^{10}$. Tanto el clásico y discutido modelo de Christaller, como las diferentes alternativas propuestas con posterioridad, incluida la nueva perspectiva de redes urbanas -que es la utilizada en este artículo- tienden a privilegiar el aspecto económico $^{11}$. Dicha visión conecta con una concepción de las ciudades que subraya ante todo su papel de centros comerciales, un rol cuyo relieve resulta evidente en las áreas más urbanizadas de la Europa bajomedieval -como Flandes y el centro y norte de la Península itálica donde, en efecto, la actividad comer-

${ }^{10}$ Así lo reconoce Stabel 2015,p. 314.

${ }^{11}$ Christaller 1966; Borsay 2004. 
cial tuvo un peso mayor ${ }^{12}-$, pero que parece menos adecuada para estudiar otros contextos urbanos como el hispánico o el francés ${ }^{13}$. De hecho, es indudable que incluso en regiones con un papel mayor en las redes comerciales internacionales, la jerarquización urbana responde a un conjunto de factores que sobrepasan el marco demográfico-económico y mercantil y que incluyen aspectos sociales, políticos y culturales. La combinación de dichos factores y la complejidad del fenómeno de jerarquización dificulta la posibilidad de establecer criterios concretos y fijar jerarquías dentro de las distintas áreas urbanas ${ }^{14}$.

Entre otras dificultades se añaden, por un lado, el hecho de que la jerarquización no es nunca estable o permanente, sino que se encuentra continuamente sometida a cambios y a menudo puesta en discusión por la competencia existente entre los distintos centros urbanos. Por otro, que dicha jerarquización puede entenderse asimismo como fenómeno, no tanto objetivo y mesurable, como resultado de factores simbólicos, condicionados por la propaganda política urbana y por la percepción de los contemporáneos de la existencia de un determinado orden jerárquico entre ciudades dentro de una misma área ${ }^{15}$. De hecho, los estudios acerca de ligas en regiones de centro europa donde estas federaciones tuvieron un mayor protagonismo (el Imperio Germánico, el sur de Francia y la región helvética) han insistido particularmente en el peso de los aspectos simbólicos en las relaciones interurbanas ${ }^{16}$. Esta aproximación se beneficia también de una documentación mucho más rica respecto a la comunicación y la correspondencia entre ciudades en el área centroeuropea, como muestra por ejemplo el trabajo de Laurence BuchholzerRémy sobre Núremberg a finales de la Edad Media ${ }^{17}$. Existen asimismo intentos de medir la centralidad de distintas poblaciones incluyendo aspectos inmateriales como un factor más a considerar. Jean-Luc Fray, en su estudio sobre los centros urbanos de la región francesa de Lorena hacía una propuesta

\footnotetext{
${ }^{12}$ A pesar de ello, en su estudio de 1992, Prevenier, Sosson y Boone reconocían la importancia de otros factores en el desarrollo de la red urbana flamenca y afirmaban que, aunque en fases de crecimiento el factor principal era el económico, cuando el comercio internacional se resentía o en situaciones de crisis, eran las funciones políticas y administrativas las que primaban, Prevenier, Sosson, Boone 1992.

${ }^{13}$ No por casualidad, la historiografía francesa ha hecho mayor énfasis en la jerarquización de carácter político y administrativo Favier 2004.

${ }^{14}$ Como muestra de la actualidad de esta problemática, baste señalar la obra colectiva de futura publicación editada por Asenjo, Crouzet-Pavan y Zorzi (en prensa),

${ }^{15}$ Un ejemplo del papel de la propaganda urbana en la puesta en escena de la centralidad en Billen 2013. 2012 .

${ }^{16}$ Este enfoque es claro por ejemplo en el volumen coordinado por Buchholzer, Richard

${ }^{17}$ Buchholzer-Rémy 2006.
} 
de medición de la centralidad basada en una revisión del modelo de Christaller en la que descartaba los aspectos geométricos y matemáticos originales ${ }^{18}$. Tras exponer una larga lista de criterios de centralidad que incluía factores políticos, administrativos, militares, culturales, de culto, económicos y espaciales -entre otros-, proponía incluir un criterio toponímico que se correspondería con una suerte de "centralidad psicológica" o incluso "inmaterial", basada en el uso del nombre de una ciudad y las ideas asociadas al mismo ${ }^{19}$.

El análisis de las hermandades bajomedievales -como el de las ligas centroeuropeas- redirige la cuestión de la jerarquización, desde planteamientos que parten de índices demográfico-económicos a los que el historiador atribuye un valor específico, hacia un ámbito completamente diferente, basado en una jerarquización que se fundamenta en el reconocimiento implícito de distintos grados de autoridad y preeminencia dentro de las propias poblaciones. En el seno de estas ligas urbanas se combinan criterios de centralidad y jerarquía basados principalmente en la existencia de lazos jurídico-administrativos, la comunicación entre las ciudades y el liderazgo simbólico. No se trata en absoluto de rechazar otros tipos de análisis, sino de contrastarlos con un planteamiento diferente, que se interrogue acerca de los criterios de jerarquización urbana que ponían en juego las propias sociedades urbanas bajomedievales.

Las hermandades muestran que las redes internacionales de comercio tenían un peso muy limitado en la construcción de la mayoría de las ligas urbanas hispánicas. No hay duda de que el desarrollo económico del siglo XIII y la crisis del XIV están detrás de la consolidación de diversas hermandades y que el mantenimiento de la seguridad en los caminos, uno de sus grandes objetivos, era fundamental para los contactos comerciales entre las villas. Sin embargo, por un lado, en Castilla pocas de estas hermandades respondían a motivaciones predominantemente económicas. Las dos más conocidas son la Hermandad Vieja de Toledo, Talavera y Villa Real y la Hermandad de la Marina de Castilla, de las cuales, mientras que la Hermandad de la Marina sí estuvo claramente dirigida al comercio internacional, la de Toledo pretendía ante todo proteger los intereses de propietarios serranos. Por otro lado, entre el elenco de objetivos del resto de hermandades, los económicos aparecen en segundo lugar, por detrás de los defensivos y, a menudo, se plantean más en

\footnotetext{
${ }^{18}$ Fray 2006. Otro estudio comparativo que intenta medir la centralidad de las ciudades en una región actualizando el modelo de Christaller es la obra ingente dirigida por Monika Escher y Frank G. Hirschmann sobre el área de Francia oriental y el oeste del Imperio germánico durante la baja Edad Media, Escher, Hirschmann 2005.

${ }^{19}$ Fray 2006, pp. 472-473. El análisis de los distintos criterios de centralidad que propone se halla en las pp. 51-148.
} 
términos de asegurar bienes y propiedades que dirigidos al fomento del comercio. Objetivos de defensa mutua y asistencia judicial que, por otra parte, son muy parecidos a los elencados en los acuerdos de ligas contemporáneas en centroeuropa y que deberían alertarnos de la necesidad de estudiar ambos fenómenos con más exhaustividad desde una perspectiva comparativa ${ }^{20}$.

En este artículo se proponen cuatro niveles de jerarquización que pueden ser analizados a través del estudio de las hermandades medievales. En primer lugar, la jerarquización sobre el territorio. Esta jerarquización se manifiesta tanto al distinguir entre los entes que son o no considerados con entidad suficiente para asociarse en calidad de hermano, como a través del aparato organizativo de administración fiscal, militar y judicial que progresivamente irán desarrollando las hermandades. Dicho aparato se sustenta sobre criterios piramidales y sobre la asunción de ámbitos jurisdiccionales preexistentes que, a su vez, se ven reforzados al ponerse en práctica la organización hermandina. En segundo lugar, se produce una jerarquización entre los concejos hermanados. En tercer lugar, la proliferación de hermandades menores permite hablar también de jerarquías entre unas hermandades y otras que, en definitiva, plasma una prelación en la relevancia de las diferentes áreas urbanas a nivel del reino. Finalmente, la proliferación de normativas que insisten en los privilegios de los hermanados, junto a las medidas de presión contra los no hermanados, promueve una jerarquización también entre los concejos y territorios incluidos y excluidos en la hermandad.

Cuestión fundamental -que solo podemos responder en parte- es en qué medida la jerarquización que presentan las hermandades se correspondía con criterios dictados por fuerzas de poder ajenas o paralelas a las ciudades: el rey y las cortes principalmente. En este sentido es destacable que existen asimismo grandes diferencias en la relación de sujeción y dependencia con ambas instituciones a lo largo de la historia de las hermandades. Sin detenernos a discutir una cuestión que requeriría mayor espacio del que disponemos y que ha sido suficientemente glosada por otros autores, lo que es indudable es que las hermandades se mostraron en ocasiones considerablemente autónomas e incluso pretendieron arrogarse autoridad para imponer exigencias a las cortes y al rey o sus tutores, en especial en 1295 y entre 1466 y 1469 , por no hablar del periodo comunero. Esa pretensión de independencia y autoridad no significa, por otra parte, que estuvieran libres de los esquemas concebidos por la corona o las cortes respecto a la organización que debían mantener las hermandades, pero en este caso debe entenderse más como un acervo

\footnotetext{
${ }^{20}$ En el estudio dirigido por Konrad Ruser sobre ligas alemanas, los acuerdos de estas Städtebünde tienen siempre en común la asistencia mutua en el ámbito defensivo y judicial, asî como el recurso al arbitraje. Ruser 1979-2005; cf. en Buchholzer-Rémy, Richard 2012, p. 6.
} 
cultural y político compartido, que como una falta de autodeterminación por parte de las ciudades. Como se verá a lo largo de este artículo, es posible que la contradicción más evidente no se produjese entre la concepción regia o de las cortes y la defendida por las hermandades, sino entre las propuestas de la junta general frente a las prácticas y costumbres consolidadas en el seno de las distintas redes urbanas y los numerosos concejos que participaban de las hermandades generales.

\section{LAS JERARQUÍAS INTERURBANAS EN LAS HERMANDADES ENTRE LOS SIGLOS XIII-XV}

\subsection{Los precedentes}

Aunque la documentación relativa a los precedentes de las hermandades es limitada y problemática, no parece descabellado afirmar que la jerarquización entre ciudades aparece en estas asociaciones desde sus inicios. Sin embargo, dicha jerarquización se muestra mucho más desarrollada a finales de la Edad Media. Podría decirse que, en general, se observa una evolución desde unas asociaciones menos encorsetadas $-\mathrm{y}$ que por ello mantienen una mayor apariencia de paridad-, hacia la creciente regulación de una organización compleja, en la cual, junto a una mayor definición de los mecanismos internos, se refuerzan una serie de elementos simbólicos que subrayan la preeminencia de unos centros urbanos sobre otros.

Las asociaciones de finales del siglo XIII tienen un carácter más laxo, lo que unido a la inicial apertura de sus juntas, antes de que se establezcan cuotas de representantes para cada uno de los miembros de la hermandad, indica una situación mayor de paridad, o al menos una escenificación limitada de las jerarquías interurbanas en el seno de las hermandades.

La primera Hermandad General documentada es la que en 1282 el futuro Sancho IV reunió con la intención de enfrentarse a su padre Alfonso X y asegurar sus derechos de sucesión al trono frente a las pretensiones de los infantes de la Cerda. Antes de esta hermandad se produjeron otras experiencias previas entre las cuales el estudio clásico de Julio Puyol y Alonso destacaba dos leyes del fuero de Salamanca (la CCLXVI y la CCCVIII), reproducidas de forma similar en el Fuero de Sepúlveda. En ellas se establecía lo que habían de cobrar los caballeros que fueran a las juntas celebradas en distintas localidades. Como explicaba Puyol, este documento prueba la existencia de una comunidad de intereses entre Salamanca y las ciudades y villas de Arévalo, Medina del Campo, Olmedo, Coca, Toro, Zamora, Segovia, Sepúlveda, Toledo, Palencia, León y Burgos. Una comunidad de intereses materializada 
en juntas que habían de ser periódicas, celebrándose alternativamente en cada una de esas localidades y acudiendo representantes de los distintos municipios. Puyol deduce que estas juntas solo pueden tratarse de una hermandad, al margen de que fuera o no reconocida con tal nombre ${ }^{21}$.

En su también clásico trabajo de 1951, Luis Suárez Fernández publicó unas cartas de hermandad establecidas entre Escalona y las ciudades de Ávila, Segovia y Plasencia ${ }^{22}$. Las cartas fueron copiadas en un manuscrito de la Biblioteca del Colegio Mayor de Santa Cruz de Valladolid, donde se apuntó como fecha aproximada 1200. Los objetivos de dichas cartas incluyen asegurar el ejercicio del derecho por parte de los vecinos de una ciudad dentro de la otra, buscar la protección del ganado y los pastores dentro de los límites de los municipios hermanados y desarrollar una especie de justicia intermunicipal mediante procedimientos de arbitraje.

$\mathrm{Al}$ margen de las diferencias entre ambas experiencias y las hermandades con múltiples ciudades de finales del siglo XIII, lo que interesa desde el punto de vista de este estudio es que ya en torno a 1200 existen pruebas de intentos autónomos asociativos entre municipios y que, en esta fase inicial, no hay ninguna evidencia del establecimiento de jerarquías entre dichos municipios. El fuero salmantino sugiere que las juntas se sucedían indistintamente en las diferentes localidades partícipes de esa suerte de comunidad de intereses y las cartas de hermandad de Escalona muestran acuerdos simétricos en lo que se refiere a las condiciones para los vecinos de una y otra localidad. Aunque no hay señas de jerarquización, dichas asociaciones tendrían el efecto de estrechar las relaciones entre ciudades, conformando áreas de influencia mutua o potenciales redes urbanas, que luego contribuirían a configurar conceptos como el de provincia.

Más cercano a la Hermandad General de 1282 es el caso de la Hermandad Asturiana estudiada por Eloy Benito Ruano ${ }^{23}$. El 14 de mayo de 1277, se firmó una carta de hermandad entre los concejos de Avilés y las pueblas de Pravia, Grado, Salas, Somiedo, Valdés, Tineo, Cangas y Allande en la localidad de La Espina ${ }^{24}$. La carta mostraba ya la preocupación por las alteraciones en los reinos y señalaba como objetivos no admitir en sus municipios a ricos hombres o caballeros contrarios al monarca, para lo cual se convocaría a apellido a las demás villas y pueblas si fuera necesario. Asimismo se establecía una serie de procedimientos judiciales y una reunión anual en La Espina.

\footnotetext{
${ }^{21}$ Puyol 1913, pp. 17-18.

${ }^{22}$ Unas de esas cartas fueron publicadas en Sánchez 1926; las otras, en Suárez 1951, pp. 46-52.

${ }^{23}$ Benito 1972.

${ }^{24}$ Ibidem, pp. 17-18.
} 
Aunque en estos momentos la carta no refleja una jerarquía entre los miembros hermanados, los acuerdos entre Avilés y Oviedo en 1282 prueban que ambas ciudades se consideraban cabeza de las respectivas hermandades a las que pertenecían.

\subsection{El periodo clásico de las hermandades (1282-1325)}

La Hermandad General de 1282 inaugura el periodo álgido de las hermandades. Es de sobra conocido tanto el contexto político -la revuelta del futuro Sancho IV contra su padre Alfonso X y las pretensiones territoriales de los infantes de la Cerda-, como el debate acerca de las motivaciones de las ciudades, entre ellas la resistencia a los intentos centralizadores de Alfonso $\mathrm{X}^{25}$. En las Cortes de Valladolid de 1282 Sancho IV aunó los apoyos del clero, la nobleza y las ciudades, reunidos en distintas hermandades, para imponerse a su padre que quedó en una situación de poder precaria hasta su muerte en 1284.

Los objetivos de la Hermandad General de 1282 incluyen la defensa de los fueros frente a la obra legislativa alfonsina y de la jurisdicción local frente a los oficiales regios; la defensa mutua frente a amenazas y enajenaciones por parte de personas poderosas; y la oposición a pedidos e impuestos nuevos como los pretendidos por la reforma fiscal de Alfonso X. A pesar de las diferencias entre las distintas hermandades $\mathrm{y}$, en especial, con las que posteriormente aparecerán en el siglo XV, estos elementos ya presentes en 1282 se repiten consistentemente en las futuras hermandades, entre otras razones por la similitud entre las ordenanzas y acuerdos de estas instituciones. Aunque hay pocos elementos desarrollados respecto a la organización interna de la Hermandad, aparecen asimismo las juntas anuales y la obligatoriedad de que cada miembro enviase sus personeros, obligación que es reforzada imponiendo penas de mil maravedís a aquellos que no acudieren.

El 27 de mayo se forma la Hermandad de Castilla, compuesta por 65 concejos. La unión de esta con la Hermandad de León se conoce por un acuerdo de 8 de julio de $1282^{26}$. Paralelamente, proliferan numerosas hermandades entre nobles y concejos. Estas últimas son en realidad hermandades con un concejo principal y las villas y lugares bajo su influencia directa o jurisdicción. Así, el Maestre de Santiago Pedro Núñez hizo hermandad con el concejo de Segovia y las villas del obispado, con el concejo de Madrid y las villas

\footnotetext{
${ }^{25}$ Acerca de esta discusión véanse, entre otros, Mínguez 1990; González 1992; Asenjo 1997.

${ }^{26}$ González 1992, pp. 54-58.
} 
de su arcedianato, o con Toledo y sus aldeas ${ }^{27}$. Se documentan también las hermandades asturianas de Avilés y Oviedo estudiadas por Benito Ruano, con la salvedad de que al menos la de Avilés existía desde antes de 1282. El acuerdo de paz y amistanza entre Avilés y Oviedo con sus respectivos hermanados revela tanto la preeminencia de ambas ciudades sobre el resto de sus respectivas hermandades, como la aparición de acuerdos entre hermandades al margen de la iniciativa del infante don $\mathrm{Sancho}^{28}$. Las ciudades andaluzas, por su parte, se constituirán también en hermandad junto a miembros de la nobleza, subrayando el propósito de defender la frontera ${ }^{29}$. La hermandad suscrita el 10 de mayo de 1282 incluía los concejos de Córdoba, Jaén, Baeza, Úbeda, Andújar, Arjona y Santisteban del Puerto ${ }^{30}$. Todas estas hermandades apoyaron al infante don Sancho, mientras que Sevilla y Murcia, leales a Alfonso X, firmaron una hermandad entre ellas.

La carta de hermandad del reino de Castilla y la unión y el pleito homenaje por parte de la de León y Galicia se conservan en la copia dada a la villa de Nájera, publicadas por González Mínguez ${ }^{31}$. El mismo acto se halla también en otra carta entregada al maestre don Pedro Núñez y a la orden de Santiago, publicada por Álvarez de Morales ${ }^{32}$. Una de las diferencias entre ambas versiones es el pleito homenaje contenido en las mismas. Mientras que en la conservada en Nájera es la Hermandad de Galicia y León la que hace pleito homenaje en la de Castilla, en la del maestre don Pedro Núñez es la Hermandad de Castilla la que hace pleito homenaje en la de Galicia y León. Esta diferencia debe entenderse como resultado de la forma habitual de realizar un pleito homenaje recíproco. Dicha reciprocidad en el acto de constitución de la unión permite afirmar que formalmente se mantuvo la igualdad entre ambas hermandades.

Con la muerte de Alfonso X en 1284, las hermandades se convirtieron en una fuerza que incomodaba a Sancho IV, toda vez que ya no las necesitaba. Un nuevo acuerdo el 1 de septiembre de 1284 entre las hermandades de los reinos de Castilla, León, Galicia, Toledo, Extremadura y Andalucía, mostró la intención de estas formaciones, no solo de perdurar, sino de tener

${ }^{27}$ Ibidem, p. 31

${ }^{28}$ Benito 1972.

${ }^{29}$ Esta presencia de poderes ajenos a la ciudad dentro de las hermandades es similar a los casos conocidos para el área alemana, donde las ligas urbanas que incluyeron a otros interlocutores políticos fueron habituales y han podido ser estudiadas con más profundidad gracias a la mayor riqueza de la documentación bajomedieval en estas ciudades. Véase, por ejemplo, Hardy 2014.

30 Acerca de las hermandades andaluzas véanse García 1985; Sanz 1978.

${ }^{31}$ AMN, doc. 5. Publicado por González 1992, pp. 54-58.

${ }^{32}$ Álvarez 1974, pp. 267-269. 
un protagonismo político aún mayor, como reunión paralela a las cortes e incluso convergente, sugiriendo en el acuerdo que las hermandades hicieran coincidir su próxima reunión con la de las cortes del reino ${ }^{33}$. En dicho acuerdo, León y Galicia ya no aparecen unidas en una hermandad conjunta y se habían sumado Toledo, Extremadura y Andalucía, representando un elenco de las distintas áreas o redes urbanas de los reinos. La reacción de Sancho IV fue su supresión. Esto no evitó la existencia de hermandades locales como las que Salvatierra establece en la región alavesa para la defensa mutua ${ }^{34}$, pero sí que hizo desaparecer las hermandades generales hasta la defunción del propio Sancho IV. Será a su muerte, con la minoría de Fernando IV, cuando se abra un nuevo período de hermandades, estas ya de carácter espontáneo frente a las de 1282 que habían sido auspiciadas por el infante Sancho.

La proliferación de hermandades a partir de 1295 confirma los aspectos ya apuntados en torno a 1282: en primer lugar, la existencia clara de diferentes redes urbanas dentro de los reinos hispánicos; en segundo lugar, un sistema interno que reconoce la jerarquización dentro de cada una de estas redes; y en tercer lugar, distintos niveles de asociación de las localidades que se insertan a la vez en hermandades menores, mayores y generales. Dichas redes están delimitadas conforme a criterios de cercanía, pero también de una mayor intensidad de intercambios y en unas líneas de afinidad basadas en modelos urbanos que comparten ciertos rasgos económicos, sociales y políticos. Bajo este esquema, una localidad asturiana como la puebla de Pravia estaría desde 1277 oficialmente incluida en una red urbana cuya cabeza era Avilés. En 1282, por virtud del acuerdo entre las hermandades de Avilés y Oviedo, Pravia se integraría en una asociación de mayor alcance que abarcaba la región asturiana y que le permitiría, en 1283, contar con el respaldo de los hermanados para imponer a Oviedo el respeto a sus derechos, así como a los derechos de Avilés ${ }^{35}$. Al mismo tiempo, si no desde 1282 cuando no aparecen explícitamente localidades asturianas dentro de la Hermandad General, al menos desde $1295^{36}$, Pravia, junto al resto de los municipios con los que ya se encontraba previamente hermanada, forman parte de la Hermandad de León y Galicia que, a su vez, conforma una de las tres grandes hermandades de los reinos unidas en la Hermandad General: la de Castilla, la de León y Galicia y la de Extremadura y el arzobispado de Toledo, todas ellas reconocidas en las Cortes de Valladolid de $1295^{37}$. El ejemplo de Pravia sería trasladable a la

\footnotetext{
${ }_{33}^{3}$ AMN, doc. 6. Publicado por González 1992, pp. 58-60.

${ }^{34}$ Martínez 1973.

${ }^{35}$ Benito 1972, p. 20.

${ }^{36}$ Ibidem, pp. 23-24.

${ }^{37}$ Cortes de Valladolid de 1295, cap. 12.
} 
multitud de concejos insertos en las numerosas hermandades menores, como la establecida por los concejos de Salamanca, Alba de Tormes y Zamora ${ }^{38}$.

Por otra parte, en 1295 es ya innegable la existencia de una cabeza por cada una de las hermandades mayores. La carta de hermandad de las villas de Castilla, fechada a 6 de julio de 1295 reconoce la primacía de Burgos como cabeza de Castilla y su preeminencia dentro de la hermandad se materializa a través de tres aspectos de gran carga simbólica: en primer lugar, se deja al concejo de Burgos como depositario del sello de la hermandad, en segundo lugar, se le hace depositario asimismo de la carta original de hermandad y, en tercer lugar, se establece como lugar para las reuniones anuales de la junta, a la que habían de acudir los representantes o personeros del resto de concejos ${ }^{39}$.

Solo seis días después se reunían en Valladolid los procuradores de los concejos leoneses y gallegos para hacer una hermandad de los reinos de León y de Galicia, cuya carta reproducía en su mayor parte los términos contenidos en la de la Hermandad de Castilla ${ }^{40}$. De nuevo se reservaba el liderazgo a una ciudad, en este caso León, que quedaría como depositaria del sello y la carta de la hermandad ${ }^{41}$. En los meses posteriores se establecieron otras hermandades que recreaban otras áreas urbanas del reino. En agosto de 1295, la Hermandad entre los concejos de la Extremadura castellana y el arzobispado de Toledo ${ }^{42}$; en octubre la Hermandad de Murcia, que reunía a los municipios de Murcia, Cartagena, Lorca, Alicante, Mula, Guardamar, Molina Seca y Alhama; en abril de 1296 la Hermandad de Cuenca; y en mayo de ese año la de Santander, compuesta por Santander, Laredo, Castro-Urdiales, Vitoria, Bermeo, Guetaria, San Sebastián y Fuenterrabía $^{43}$. La tardía Hermandad Riojano-alavesa se formó en Haro el 6 de agosto de 1296. César González Mínguez considera que esta última fue el resultado de la falta de eficacia de la Hermandad General, que llevó a estas localidades a fundar una hermandad cuya prioridad fuera la efectiva persecución de los malhechores ${ }^{44}$. Esta lectura apunta a un problema que aparece también entre las hermandades del siglo $\mathrm{XV}^{45}$ y que denota fricciones o desajustes entre los objetivos a nivel local o comarcal, frente a los objetivos, los criterios y, sobre todo,

${ }^{38}$ González 2006, p. 23.

${ }^{39}$ Puyol 1913, pp. 27-29.

${ }^{40}$ AML, núm 49.

${ }^{41}$ Puyol 1913, pp. 29-32.

${ }^{42}$ García 1969.

${ }^{43}$ Puyol 1913, pp. 33-34.

${ }^{44}$ González 2006, p. 25.

${ }^{45}$ A la desconfianza de los concejos frente a los organismos centrales de la Hermandad General atribuía Luis Suárez el fracaso de la Hermandad General en 1469, lo que habría llevado a una atomización en hermandades menores y, finalmente, a un intento de reorganización auspiciado por Enrique IV con las ordenanzas de Villacastín en 1473. Suárez 1951, pp. 43-44. 
la efectividad de las hermandades generales. Aunque las hermandades locales y menores parecen el resultado "natural" de la cercanía y las similares condiciones socioeconómicas de ciertos núcleos, no es menos cierto que la volatilidad de estas hermandades y los frecuentes cambios insertándose en hermandades generales o atomizándose en otras de carácter más local, muestran su versatilidad y la conciencia de que en función de los problemas convenían diferentes alianzas. Si la junta general tendía a creer que la unión hacía la fuerza, en el ámbito local parece que se confiaba más en la resolución de los problemas propios a través de las hermandades menores.

El reinado de Fernando IV se considera el periodo en el que estas hermandades adquirirán mayor poder político. No solo son refrendadas por las Cortes de Valladolid en 1295, sino que en las Cortes de Cuéllar de 1297 María de Molina y el tutor del rey, el infante don Enrique, tuvieron que aceptar un consejo permanente de doce hombres buenos que serían nombrados por los concejos. El reconocimiento ulterior en las Cortes de Burgos de 1302, que concedía a los concejos el derecho a convocar a la hermandad general libremente, marca el inicio de un descenso en el protagonismo de las hermandades que se ha atribuido a una posible relajación de las reivindicaciones concejiles debida a los numerosos privilegios concedidos durante el periodo que habría satisfecho sus expectativas.

La prematura muerte de Fernando IV abre nuevamente un periodo de inseguridad marcado por las disputas por la tutoría del rey niño. La Hermandad General de Andalucía se constituye ya en 1312 mostrando gran autonomía en la resolución de los conflictos en la frontera granadina y llegando a reunir en su momento álgido, en 1319, a la mayoría de concejos del Alto y del Bajo Guadalquivir, al Adelantado de la Frontera, a los nobles más destacados del área y a las órdenes militares ${ }^{46}$. En el área castellana, don Juan, hermano de Sancho IV, buscará los apoyos de las ciudades llegando a un acuerdo con Burgos a través de Juan Núñez. Posteriormente, estableció un acuerdo con la Hermandad de León en 1313, antes de la reunión de las cortes en Palencia, donde se había de dirimir la cuestión de la tutoría. El 15 de enero de ese año se reunieron en Benavente los procuradores de una serie de municipios que incluían a los más destacados de la región leonesa (León, Zamora, Astorga, Mansilla y Benavente) e hicieron hermandad con el infante don Juan, con el infante don Felipe y con don Pedro Ponz y don Juan Núñez ${ }^{47}$. Juan Ignacio Ruiz de la Peña considera que, al fijar las reuniones de la hermandad en la villa de Benavente esta quedaba convertida así en centro o capitalidad de la

${ }^{46}$ García 1985. Esta hermandad sería una continuación de la ya existente en 1282 y a la que en 1295 se adhirió Écija: Sanz 1978.

${ }^{47}$ AML, núm. 694. El cuaderno de la hermandad fue publicado en Ruiz 1978, pp. 157-163. 
institución supramunicipal que se crea, como lo habían sido Burgos, León y Alcalá respecto de las tres Hermandades mayores de $1295^{48}$.

Las sedes de las juntas son sin duda un aspecto de gran carga simbólica, asociada al reconocimiento de una jerarquía interna de la hermandad, pero que va a tener distinto peso a lo largo del periodo. En el fuero de Salamanca las juntas parecían realizarse en cualquiera de los municipios asociados, lo que supondría un modelo de alternancia. Tampoco parece haber una sede fija en las hermandades de 1282-1284, sino que en cada junta se establece dónde tendrá lugar la próxima (en la junta de Medina del Campo en septiembre de 1284 se establece que la próxima sea en Sahagún el día de San Miguel, y otra tendrá lugar en Carrión en diciembre de ese mismo año). Sin embargo, en las hermandades nacidas en 1295, como se señaló, la sede de la junta, junto al sello y las cartas originales de hermandad, muestran ya una suerte de capitalidad y preeminencia que parece recaer en ciudades con un particular capital simbólico y prestigio histórico. Si la sede de las juntas seguía teniendo el mismo significado, el traslado de León a Benavente sería una muestra de la competencia entre ambas ciudades por ganar influencia dentro de la hermandad y mostraría una recién adquirida (y potencialmente provisional) ascendencia de la villa de Benavente. Sin embargo, la situación geográfica de Benavente, equidistante entre León, Astorga y Zamora, sugiere que su elección podría deberse a motivos logísticos y a la conveniencia de trasladarse a esta villa, en lugar de a la de León. De hecho, el cuaderno contiene otra información que parece confirmar que el traslado de la sede no equivalía a la sustitución de León como ciudad a la cabeza de dicha hermandad. En el acuerdo, la hermandad nombra por sus procuradores a Pero Rendol, procurador del concejo de León y a Gil González, procurador del concejo de Zamora y son estos, como representantes de la hermandad, quienes toman el juramento del infante don Juan y Pedro Ponz sobre los santos evangelios para, posteriormente, ser estos mismos procuradores, como procuradores de sus concejos (el de León y de Zamora) y en nombre de los otros concejos cuyos personeros están igualmente presentes y de los cuales han recibido poder, los que juran sobre los santos evangelios que guardarán y cumplirán todo lo estipulado. Igualmente todo parecen indicar que son estos dos procuradores los que ponen los sellos de cera que traen personalmente colgados, mientras el resto de procuradores tan solo firman en el acuerdo con sus nombres: E otrosy, nos los procuradores sobredichos posiemos en el nuestros seellos, los que los trayemos de çera colgados, e los que los non trayemos posiemos en el nuestros nonbres con nuestras manos ${ }^{49}$. La carga simbólica de este

${ }^{48}$ Ibidem, p. 152

${ }^{49}$ Ibidem, p. 162. 
acto parece sin duda mucho mayor que el hecho de celebrar la junta en la villa de Benavente, a pesar de que también la celebración en un determinado lugar tuviera un valor intrínseco. La elección como sede de las juntas de localidades situadas en una geolocalización estratégica o de especial conveniencia para la mayoría de los concejos hermanados se repite en otros casos. Por ejemplo, la Hermandad Asturiana de 1277 se reúne en el lugar de La Espina, aún cuando el acuerdo con Oviedo en 1282 confirma que el municipio principal era Avilés ${ }^{50}$. Del mismo modo, es también la accesibilidad para los distintos hermanados el motivo de disputas acerca de donde habría de reunirse la Hermandad Vieja de Toledo, en la que Ciudad Real, a menudo el tercero en discordia dentro de la confederación, no estaba de acuerdo ${ }^{51}$. En cualquier caso, aún cuando las razones para su elección respondieran a cuestiones prácticas, no hay que desdeñar el valor simbólico que tendría actuar como sede de la junta, función que, no en vano, las hermandades mayores de 1282 habían reservado para León y Burgos y que también tendría connotaciones jerárquicas en las hermandades del siglo $\mathrm{XV}$.

La deferencia hacia los procuradores de Zamora y León en la Hermandad de León tuvo su paralelo en la Hermandad de Castilla con respecto a otros dos procuradores, uno de los cuales representaba a la ciudad de Burgos. Días después de la firma de la carta de hermandad de León, el 22 de febrero de 1313, en San Pedro de Dueñas, cerca de Sahagún, hubo una nueva reunión, esta vez incluyendo a la Hermandad de Castilla. En ella el infante don Felipe, don Fernando y don Alonso hicieron juramento de pleito homenaje en el infante don Juan, sobre los Evangelios, a los procuradores de las Hermandades de Castilla y León. Por la de Castilla lo hicieron Andrés Pérez y un tal García de Burgos. Aunque según la transcripción de Ruiz de la Peña no es posible conocer por qué ciudad era procurador Andrés Pérez, sabemos que al menos García lo era por la ciudad de Burgos. Por su parte, en nombre de la Hermandad de León firman nuevamente Pero Rendol, especificando que era de León, y Diego López, de Zamora. Se subrayaba de esta forma que actuaban a la vez como procuradores de sus ciudades particulares y de la hermandad y se destacaba el lugar de León, Zamora y Burgos dentro de la Hermandad General. La Hermandad General de Andalucía no será distinta en este sentido puesto que en la carta de hermandad de 1320 establecía que para tratar la cuestión de Tarifa y Gibraltar, fueran Sevilla y Córdoba por sy, e por todos los de la hermandat, a pedir merced a la reina ${ }^{52}$.

\footnotetext{
${ }^{50}$ Benito 1972,p. 19.

${ }^{51}$ Sánchez 1987, pp. 69-70.

${ }^{52}$ ADMS, leg. 742. Carta de hermandad del 23 de abril de 1320, firmada en Peñaflor y publicada por García 1985, pp. 370-373.
} 
Por otra parte, estos elementos que remiten a la atribución de cierta preeminencia e incluso de la reserva del derecho a representar al resto de la hermandad a ciertos concejos, conviven aún con muestras de cierta laxitud en la organización y en las formas de representación de los diversos municipios que dan pie a un mayor peso del resto de localidades hermanadas. La muestra más evidente es la falta de definición del número de personeros. Si bien cartas como la de la Hermandad de Avilés aclaraba que cada municipio enviaría dos procuradores, otras hermandades no precisan un número de representantes. En el caso de la Hermandad de León de 1313 esto da pie a un número dispar de procuradores por cada una de las ciudades y villas partícipes. Disparidad que tampoco se corresponde con criterios jerárquicos sino que ha de atribuirse, más bien, a las decisiones internas de cada concejo a la hora de nombrar y otorgar poder a los representantes que habrían de acudir a la junta. En este caso aparecen solo dos procuradores por León, pero llegan a ser cinco por Zamora y seis por Benavente ${ }^{53}$. Si la presencia mayor de procuradores benaventanos parece natural al producirse en dicha localidad la junta, la diversidad de representantes por parte del resto de villas y ciudades confirma que es una cuestión que trasciende la conveniencia logística y la carga económica que supondría el traslado de dichas personas para los concejos y se mezcla con cuestiones internas de los gobiernos urbanos y sus sistemas de reparto de poder, asignación de cargos y concepto de representación.

No solo la capitalidad y el número de procuradores, también el modo de subdividirse en distintas hermandades, fluctúa a lo largo de cortos periodos de tiempo. En la Hermandad General firmada en las Cortes de Burgos en 1315 se establecen nuevas subdivisiones con la intención de realizar juntas separadas, una decisión que respondería a la dificultad de enviar representantes a las juntas generales anualmente. Así, en 1315 se propone realizar juntas por separado: por un lado Castilla y Toledo con sus Extremaduras, y por otro León, Galicia y Asturias, que se reunirían con regularidad bianual, una vez en León y otra en Benavente. Volvía León a recuperar su papel como sede, aunque fuera de forma compartida, quizás favorecido por la inclusión de los municipios astures y gallegos, cuyo traslado hasta la ciudad leonesa resultaría menos oneroso que hasta Benavente ${ }^{54}$.

La llegada de Alfonso XI a la mayoría de edad traerá una nueva prohibición de las hermandades en las Cortes de Valladolid de 1325, pero esta no afectó a las hermandades de tipo económico como la de colmeneros de Toledo, Talavera y Ciudad Real, que merece especial atención.

${ }^{53}$ Ruiz 1978, p. 162.

${ }^{54}$ Ruiz 1978. 


\subsection{La Hermandad vieja de Toledo, Talavera y Ciudad Real}

Entre las múltiples experiencias hermandinas destaca la de la Hermandad Vieja de Toledo, Talavera y Ciudad Real ${ }^{55}$. Se trata de una hermandad cuyo objetivo era eminentemente económico y que estaba dirigido a proteger los intereses de los propietarios en los montes de estas tres localidades - en especial los colmeneros - y a perseguir a los malhechores en despoblado ${ }^{56}$. Si bien es cierto que era una hermandad de personas y no de municipios, no dejaba de reflejar igualmente una suerte de jerarquización interurbana. De hecho, se trata de un caso especialmente interesante por la estabilidad y larga duración de esta institución. José María Sánchez Benito descarta distintas propuestas acerca de un origen más remoto y mitificado de esta Hermandad y señala que el primer documento que confirma la existencia de la misma es una carta suscrita en Toledo en el año 1300, seguida poco después ese mismo año de una carta de hermanamiento entre la hermandad de Toledo y la de Talavera. Ciudad Real se hermanaría a ambas en $1302^{57}$. Aunque aparece por lo tanto durante el periodo clásico de las hermandades, sus considerables diferencias respecto a las ligas de tipo político favorecerán su continuidad durante la baja Edad Media y la Edad Moderna. Esta longevidad, unida a una mayor producción documental, permite observar una clara jerarquización interna, cuya evolución sin embargo no es fácil datar. Aunque José María Sánchez Benito no considera que sea una institución unitaria ni que posea un aparato institucional y jerárquico conjunto ${ }^{58}$, por otra parte, él mismo aporta considerable información respecto a las disputas internas a las que dio lugar la diferente preeminencia que se otorgaba a cada una de las ciudades en las reuniones conjuntas.

$\mathrm{Al}$ igual que en las hermandades generales, también esta carecía en sus inicios de normas fijas respecto al número de representantes por cada concejo. De hecho, inicialmente las juntas estaban abiertas a todos los hermanados lo que se comprendería como una forma de demostrar su fuerza: Sánchez Benito señala incluso que la asistencia multitudinaria a las asambleas le confería carácter de alarde ${ }^{59}$. Las dificultades y cargas que el traslado de tal número de personas engendraría dio lugar a que se optara por el envío de representantes, pero sin limitarlos a una cifra concreta, incluyendo a un número variable de alcaldes, fieles, mayordomos, cuadrilleros, procuradores, caballeros y hermanos.

\footnotetext{
${ }^{55}$ Sánchez 1987. El mismo autor ha publicado una colección de documentos relativos a esta hermandad: Sánchez 1990.

${ }^{56}$ Sánchez 1987, p. 313.

${ }^{57}$ Sánchez 2005, pp. 212-214.

${ }^{58}$ Sánchez 1987, p. 59.

${ }^{59}$ Ibidem, p. 64.
} 
Aparentemente, las ordenanzas y el sistema de mediación entre las tres ramas reproducían el funcionamiento de una asociación entre pares ${ }^{60}$. De hecho, $\mathrm{M}^{\mathrm{a}}$ del Carmen Pescador del Hoyo consideraba que el mayor error en la organización de esta hermandad es que carecía de una jerarquía reconocida ya que no especifican, posiblemente por no llegar a un acuerdo, quién debía ejercer la autoridad suprema cuando todos salian en persecución de malhechores y a quién tenían que acatar ellos mismos ${ }^{61}$. Sin embargo, más allá de esta parente igualdad, con las consiguientes disputas y desacuerdos, hay numerosas evidencias de que las reuniones de las tres hermandades (llamadas llegas) reproducían un protocolo cargado de simbolismo, en el que se reconocía claramente un orden jerárquico entre ellas. Conocemos el simbolismo desplegado durante las juntas a través de las quejas y resistencias presentadas por los representantes de Ciudad Real a finales del siglo XV y principios del XVI, lo que dificulta la posibilidad de establecer desde cuándo la hermandad observaba dicha jerarquía o cuándo empieza a ser reconocida a través de dichos símbolos.

Ya en 1455, según Paz y Meliá, se había producido un desencuentro porque la hermandad de Villa Real se oponía a que los alcaldes de Toledo fueran los únicos en llevar varas en la junta ${ }^{62}$. Aunque se justificó por ser Toledo la sede de la reunión, tuvieron que ceder de cara a la próxima junta en la que ninguno de los alcaldes podría acudir con vara. En 1499 los de Ciudad Real cuestionaron el orden y el lugar que los representantes de las distintas hermandades ocupaban en las juntas. Según Sánchez Benito, desde tiempos antiguos la hermandad de Toledo ocupaba el lugar central, la de Talavera se situaba a la derecha y la de Ciudad Real a la izquierda ${ }^{63}$. Además denunciaban que también existía desigualdad en el tamaño de las banderas que cada hermandad llevaba a la junta. Respecto a la primera cuestión, en 1499 Toledo y Talavera se opusieron a realizar cambios, defendiendo la costumbre por considerar que no era en perjuicio de nadie. Sin embargo, cuando Ciudad Real reiteró sus quejas en 1505, hubieron de resolver una nueva distribución que seguía manteniendo la posición central de los alcaldes toledanos, los talaveranos a la derecha y los de Ciudad Real a la izquierda, pero variaba posteriormente el lugar del resto de caballeros que acudían a la junta, de forma que se satisfacía en cierta medida a Ciudad Real sin renunciar por completo a la posición privilegiada de Toledo, seguida de Talavera. En cuanto a las banderas, se determinó que fueran todas de igual tamaño.

\footnotetext{
${ }^{60}$ Ibidem, pp. 89-94.

${ }^{61}$ Pescador 1971, p. 421.

${ }^{62} \mathrm{Paz}$ 1897, p. 102.

${ }^{63}$ Sánchez 1987, pp. 81-82.
} 
La Hermandad Vieja de Toledo es el mejor ejemplo que tenemos acerca de la comunicación simbólica que se desplegaba durante las reuniones de las hermandades y en qué forma estas podían reproducir una jerarquía bien establecida entre las ciudades. Dicha jerarquía no se materializaba tan solo en estos elementos simbólicos, sino que tenía consecuencias concretas y nada desdeñables en las decisiones tomadas por la hermandad y que en el caso de la Hermandad Vieja de Toledo se pueden resumir en las frecuentes dificultades que Ciudad Real afrontó, tanto a la hora de imponer su postura dentro de la propia hermandad, como frente a fuerzas ajenas a la hermandad (como la orden de Calatrava o el arzobispado de Toledo), para lo cual hubo de requerir en diversas ocasiones el apoyo de Toledo y Talavera ${ }^{64}$.

\subsection{Las hermandades en época de Enrique IV}

Después de la prohibición de Alfonso XI, las hermandades aparecen esporádicamente en la historia castellana sin adquirir una significación similar hasta la llegada de las guerras civiles a mediados del siglo $\mathrm{XV}^{65}$. A partir de este momento se abre un nuevo periodo que pasa por la movilización de las ciudades durante los enfrentamientos de los reyes Juan II y Enrique IV con la nobleza, el intento de domesticar las hermandades por parte de los Reyes Católicos a través de la creación de la Santa Hermandad en 1476, hasta la proliferación de nuevas hermandades desde 1506 que culminan con el movimiento comunero en 1520 .

Ante la imposibilidad de extendernos más allá, en este artículo nos centraremos en el reinado de Enrique IV, periodo que, ya desde los estudios de Konrad Häbler ${ }^{66}$, ha sido identificado como un momento de especial efervescencia de las hermandades. En 1456 Enrique IV, intentando movilizar el apoyo de las ciudades, escribió a Segovia, ordenándole formar hermandad, junto a su tierra y a las ciudades de Burgos, Ávila y Palencia y las villas de Valladolid, Arévalo, Roa y Aranda, todas con sus tierras y comarcas y con las otras villas y lugares de esa parte de los puertos ${ }^{67}$. Es evidente la intención de

\footnotetext{
${ }^{64}$ Algunos ejemplos de estos conflictos en Sánchez 1987.

${ }^{65}$ Un resumen de las hermandades aparecidas entre 1325 y 1451 puede hallarse en Puyol 1913, pp. 41-45; acerca del ordenamiento de justicia de 1351 en el que no se nombran las hermandades pero se regula el apellido lo que, claramente, alude a movimientos con el carácter de hermandad, véanse González 2006, p. 30 y ss.; Álvarez 1974, pp. 98-101.

${ }^{66}$ Häbler, 1885 y 1886 . Véase también Álvarez 1985.

${ }^{67}$ Se conoce el texto a través de una carta conservada en el archivo municipal de Espinar, en la que la ciudad de Segovia comunicaba esta orden del rey al lugar del Espinar, y que fue publicada tanto por Puyol 1913, pp. 49-60; como por Álvarez 1974, pp. 271-272.
} 
Enrique IV de situar el movimiento bajo su control, pues en la carta encargaba que los ejecutores, inquisidores y jueces en la hermandad fueran los corregidores y asistentes de las respectivas ciudades: Pedro de Luján, su asistente en Burgos, Juan de Porres, corregidor en Ávila, Diego del Águila, alguacil de Segovia, y Gonzalo Mejía, corregidor de Valladolid. Asimismo, el sistema de adhesión a la hermandad que proponía se basaba en una concepción piramidal y jurisdiccional, en la que cada ciudad había de requerir a todos los lugares y concejos de la tierra bajo su jurisdicción. En efecto, Segovia envió a cada sexmo un mandamiento para señalarles que nombraran cuadrilleros, cada lugar según el número de vecinos. Sin embargo, este aparente control inicial regio, en absoluto se mantuvo a lo largo del periodo.

Nuevamente, surgieron distintas hermandades locales, sin embargo, lo más interesante del periodo son la serie de cuadernos de hermandades generales que van a proveer a esta institución una organización compleja y altamente detallada. Aunque inicialmente tan solo se habían publicado dos cuadernos de estas Hermandades, el de Castronuño de $1468^{68}$ y el de Villacastín de $1473^{69}$, José Luis Bermejo Cabrero publicó en 1988 otros cinco cuadernos de hermandad general que han permitido un conocimiento más profundo de este movimiento. Se trata de dos cuadernos de Medina del Campo (1466 y abril de 1467), uno de Fuensalida (noviembre-diciembre de 1466), uno de Cantalapiedra (diciembre de 1467) y otro de Madrigal (febrero de 1468) ${ }^{70}$. En 1951 Luis Suárez, basándose en los cuadernos de hermandades hasta entonces conocidos, consideraba que las hermandades se habían convertido en un cuerpo de guardia, perdiendo su poder reivindicativo, sugiriendo que tenían más en común con la Hermandad Vieja de Toledo que con las hermandades de 1282: De ser una liga de ciudades constituída en un momento de expansión vital, económica y política, de los municipios, ha pasado lentamente a constituir un cuerpo de policía ciudadana ${ }^{71}$. Por el contrario, los cuadernos descubiertos posteriormente reflejan una realidad muy distinta. Además del aparato organizativo que la hermandad intentó poner en funcionamiento, en parte descrito en el cuaderno de Castronuño, los otros cuadernos muestran hasta qué punto esta pretendió arrogarse una autoridad tan solo inferior a la real y similar o incluso superior a la ostentada por las cortes, tomando decisiones acerca de la subida de precios, la escasez de alimentos, las enajenaciones del patrimonio real a través de la concesión de mercedes, el acrecentamiento de oficios o en cuestiones tan peregrinas como la prohibición de compañías comerciales.

\footnotetext{
${ }^{68}$ Publicadas por Puyol 1913,pp. 105-125.

${ }^{69}$ BNM, mss. 13030, ff. 58v-69v. Publicado en Suárez 1951, pp. 72-78.

${ }^{70}$ Bermejo 1988, pp. 343-412.

${ }^{71}$ Suárez 1951, p. 45.
} 
En 1467, tras la batalla de Olmedo, se reunieron los diputados y procuradores de los reinos de Castilla y León en la junta general de Castronuño. La organización interna de la Hermandad General contenida en las ordenanzas de Castronuño muestra un sistema complejo, con diferentes niveles geográficos y con una administración que cubre aspectos judiciales, jurisdiccionales, militares y financieros. Se establecían juntas locales, juntas provinciales y una Junta General en la que se dictaban las ordenanzas. A dichas juntas estaban invitados los miembros de la hermandad (ciudades, villas, alfoces, valles, sexmos, cuartos y ochavos) a través de sus representantes.

Todo este entramado, llevó a Puyol a afirmar, con excesivo entusiasmo, que se trataba de una:

organización extensísima y compleja (...) que representa esta máquina administrativa, judicial, legislativa y militar, son circunstancias que nos indican que la Hermandad era un Estado dentro de otro, ó mejor dicho, el único Estado que entonces existía en Castilla; una verdadera convención formada por el pueblo, en vista de que los que tenían el deber de velar por él hacían todo lo posible por destruirlo ${ }^{72}$.

El problema está en discernir en qué medida esta imponente organización descrita por Puyol llegó a existir. Es decir, hasta qué punto todas estas medidas fueron puestas en práctica y con qué alcance y efectividad. La insistencia en realizar padrones que asegurasen las contribuciones económicas y militares y la necesidad acuciante de impelir a otras ciudades para que se sumaran a la hermandad muestran hasta qué punto estas disposiciones tropezaban con innumerables obstáculos y límites. Esto no obsta para que las hermandades contribuyeran a poner en funcionamiento un aparato institucional que después sería aprovechado por la corona. La prueba más evidente fue la creación por parte de los Reyes Católicos de la Santa Hermandad en 1476, con la que la monarquía se apropiaba de la infraestructura logística, pero también se beneficiaba de la aceptación previa (relativa) de las comunidades a contribuir a la formación de cuadrillas y el pago de impuestos. Así, la organización autónoma de las ciudades, desarrollando tareas que más adelante serían propias del Estado, una vez domesticada, acabaría por reforzar el dominio de la corona.

Con respecto al fenómeno de jerarquización, cuatro aspectos destacan en este periodo: la consolidación de la jurisdicción; la regulación de los representantes de los concejos y provincias estableciendo distintos niveles y categorías; la presión ejercida sobre los no hermanados, combinando los privilegios para los miembros y las medidas punitivas para los excluidos; y la

\footnotetext{
${ }^{72}$ Puyol 1913, pp. 85-86.
} 
tensión entre la reproducción de redes urbanas y el intento de reconducirlas en cuestiones como el recurso al apellido.

Se evidencia en los cuadernos de esta Hermandad General un proceso de intensificación y confirmación de la jurisdicción de ciudades y villas sobre el territorio, al diseñar una organización hermandina que descansaba sobre dicho esquema. En las ordenanzas de Castronuño la hermandad se dividió por provincias, aunque no se señalaban cuáles eran dichas provincias ni los miembros hermanados. Además de la junta general, a la que acudían los diputados y los procuradores de las provincias, existían juntas provinciales. Se establecieron ocho diputados por provincia que serían nombrados cada uno en sus provincias y confirmados en la Junta General y que tratarían apelaciones de los casos juzgados por los alcaldes de hermandad. En cuanto a la organización militar, cada municipio debía aportar un número de soldados proporcional al número de vecinos. Estas milicias estaban lideradas por capitanes locales, elegidos por los diputados de hermandad del propio lugar, bajo las órdenes de un capitán provincial, nombrado por la provincia, que a su vez estaban bajo el mando del capitán superior que sería nombrado en la junta general ${ }^{73}$.

La consolidación de la jurisdicción de las ciudades y villas sobre los territorios se vio reforzada por el sistema de repartimientos que, según las leyes de Medina del Campo de 1466, debía guardar la costumbre que las ciudades y villas tuvieran con sus tierras ${ }^{74}$. En las leyes de Madrigal de 1468 se establecía que, en el contexto de los enfrentamientos entre el bando alfonsino y enriqueño, para evitar conflictos, aunque cada concejo podría decidir libremente la obediencia a una u otra facción, en el caso de los lugares bajo la jurisdicción ordinaria de una ciudad o villa, si estos intentaban ser enajenados, la ciudad o villa principal sería socorrida por la hermandad para retener el tal lugar y [este] siga a su ciudad y villa y le sea obediente según debe ${ }^{75}$. El sistema de provincias intentaba dar una racionalidad a la organización, reconstruyendo criterios de jurisdicción desde una perspectiva central que chocaría en ocasiones con los intereses particulares de los hermanados.

Como en otras experiencias hermandinas previas, no había un número preestablecido de representantes locales. El segundo cuaderno de ordenanzas de Medina del Campo daba cuenta de los problemas surgidos por la ausencia de un número fijo de representantes por cada municipio en las juntas generales. Las leyes de Fuensalida habían pretendido limitar la influencia de los poderosos señalando que procuradores y diputados fueran personas

${ }^{73}$ Las ordenanzas de Castronuño fueron publicadas en ibidem, pp. 105-125.

${ }^{74}$ Bermejo 1988, p. 350.

${ }^{75}$ Ibidem, pp. 408-409. 
discretas, de recto juicio y no nombrados por personas poderosas, sin embargo, el resultado contraproducente había sido que cada ciudad, villa y lugar nombraba multitud de gente causando confusión. Por ello se resolvía que a partir de ahora se nombraran no más de tres procuradores y diputados por cada ciudad, dos por cada villa y uno por cada sesmo, cuarto, ochavo, alfoz o valle. En caso de que acudiesen más a las juntas generales, los procuradores de más no serían recibidos.

El nombramiento de escribanos fue otra de las fuentes de tensiones entre la junta central y los concejos. El capítulo tres del cuaderno de Fuensalida en 1466 muestra que se habían producido disputas porque ciertas ciudades y provincias pretendían tener sus propios escribanos en las juntas generales, lo que provocaba conflictos durante las negociaciones. Por ello se resolvió establecer un número máximo de seis escribanos en las juntas generales y conceder que cada provincia tuviera un escribano provincial que pudiese tomar de los escribanos generales el traslado de las escrituras que se realizasen en las juntas generales ${ }^{76}$. Sin embargo, no se zanjó la cuestión puesto que el segundo cuaderno de Medina del Campo reflejaba que los seis escribanos de las juntas generales eran de facto nombrados por ciertos concejos que no se explicitaban, por lo que el resto de ciudades, villas y lugares se sentían por agraviados dello. Por eso resolvían que en todas las juntas hubiese en cada provincia un escribano de buena fama elegido por la provincia y ante ellos pasasen los actos y escrituras necesarios en la junta y que así todas las provincias tendrían todas las escrituras necesarias. Esta medida iba también encaminada a un mejor control de las juntas provinciales y de las comunicaciones entre la central y las demás, pues se obligaba a los escribanos provinciales a acudir siempre a las juntas generales y traer razón de todo lo que hubiera sucedido en sus provincias.

En este sentido, la tensión entre un sistema de representación que tendía a privilegiar a las ciudades más insignes y un modelo paritario fue constante. Entre las medidas que reforzaban el carácter igualitario de las hermandades se halla el capítulo 25 de las primeras ordenanzas de Medina del Campo en 1466, que equiparaba a todos los alcaldes de hermandad, fueran del lugar que fueran, otorgando que todos ellos trajeran varas de la hermandad, pintadas en el extremo superior con dos saetas coloradas, para distinguirse de los jueces ordinarios. Asimismo en las segundas ordenanzas de Medina del Campo en 1467, se establecía el protocolo a seguir en las juntas generales procurando una alternancia entre las provincias que asegurase la concordia. Las juntas serían presididas por dos diputados que se alternarían diariamente y

${ }^{76}$ Ibidem, p. 361. 
estos presidentes debían ser de provincias distintas y escogidos por sorteo en la primera sesión, estableciéndose un turno para el resto de los días, para que hubiese orden. Estos presidentes otorgarían la palabra y señalarían cuándo habían de hablar y votar los demás diputados, uno por cada provincia ${ }^{77}$.

Estas medidas por la alternancia y la equidad no servían sin embargo para ocultar la preeminencia de ciertas ciudades dentro de la hermandad. En el cuaderno de Fuensalida a finales de 1466, el capítulo 38 afirmaba que para notificar a las cortes las leyes hechas por la junta, se había diputado a los procuradores de las nobles ciudades de Burgos y León como cabezas de estos reinos para ir con la embajada acordada, con un escrito dado por los escribanos y con el sello de la hermandad. Se añadía más tarde que el sello de la Junta lo tendría Burgos y sus procuradores en su nombre, así como todos los cuadernos y provisiones generales. Si bien el sello había de discurrir por todas las provincias, pasando en cada junta a una nueva provincia hasta que todas hubieran sido depositarias del sello, el orden en esta alternancia no deja lugar a dudas. En primer lugar el sello quedaría en Burgos y en la siguiente junta, realizada en Medina del Campo en abril de 1467, se ordenaba que hasta la siguiente el sello general quedase en manos de León.

En 1473 en el cuaderno de Villacastín se reiteraba la gradación en el sistema de representantes que los distintos entes hermanados habían de enviar a la junta general, se limitaba el número de alcaldes por localidad y se volvía a insistir en la regulación del apellido. A partir de ahora el número de alcaldes de hermandad sería de uno en los lugares con entre 30 y 100 vecinos y dos en los que tuvieran más de 100 vecinos. Más importante que el número de alcaldes era la jurisdicción de estos. Los de villas y lugares sujetos a ciudades y villas realengas tan solo podrían recibir querellas y apellidos en el ámbito local y en caso de hacer perseguir malhechores o prenderlos tenían que notificarlo a los alcaldes de la hermandad de la ciudad o villa de cuya jurisdicción fueren, estableciendo una sujeción que hasta ahora no existía de forma explícita. La diferencia de estatus y prerrogativas entre los alcaldes de unos núcleos y otros se cifraba asimismo en su capacidad de convocar juntas. Solo los alcaldes de hermandad de ciudades y villas notables, que fueran cabezas de reinos, arzobispados y obispados o de las ciudades y villas que solían enviar procuradores a cortes, podrían convocar a junta general a todas aquellas ciudades, villas, lugares y tierras que considerasen convenientes, tanto de su propia comarca, como de lugares más lejanos. En un segundo nivel, los alcaldes de hermandad de otras villas y lugares con jurisdicción sobre sí mismas, pero que no perteneciesen al primer grupo, podrían hacer ayuntamiento de la

${ }^{77}$ Ibidem, p. 399. 
hermandad de la villa o lugar y su tierra, pero nunca más allá. Finalmente los alcaldes de hermandad de los lugares bajo la jurisdicción de otras ciudades y villas realengas solo podrían hacer ayuntamiento de hermandad en su propio lugar. Incluso, frente a la norma aprobada en 1466 en Medina del Campo, por la que todos los alcaldes de hermandad llevarían igualmente una vara distintiva, se estableció en Villacastín que cada concejo decidiese si los alcaldes de hermandad habían de traer vara y cómo habían de traerla o si habían de llevar compañía o nombrar capitanes. Aunque esta disposición seguramente respondiera a las reticencias de los concejos a los gastos que el nombramiento de estas personas supondría, contribuía a crear distinciones entre los alcaldes de hermandad de diferentes lugares, en lugar de tender a igualarlos como había hecho la disposición de 1466.

Si dentro de la propia hermandad existía una tensión evidente entre las pretensiones de paridad y el reconocimiento fáctico a ciertas ciudades, con respecto a los municipios no hermanados la intención de excluirlos de cualquier tipo de beneficio que la hermandad aportase era una forma de diferenciarse constituyendo municipios de primera y de segunda. La actitud respecto a los no hermanados llegaba incluso a tonos beligerantes, estableciendo medidas agresivas para incentivar que todos se unieran a la hermandad, pues en dicha unión entendían que estaba la fuerza de esta institución. Por ejemplo, si un vecino de un municipio no hermanado delinquía en territorio de la hermandad sería punido, pero si era víctima y exigía justicia, no sería oído ${ }^{78}$. Algunas de esas medidas llegaban a ser tan disparatadas como la prohibición (establecida en Fuensalida en 1466) de mantener relaciones comerciales con los municipios no hermanados. Decisión que fue revocada a los pocos días de firmar el cuaderno de ordenanzas, suspendiendo su efecto hasta la próxima junta, en la cual no se volvió a discutir esta cuestión ${ }^{79}$.

Mayor éxito parece que tuvieron las medidas para persuadir a otros concejos a través de la negociación. En el primer texto de Medina del Campo son aún pocas las ciudades importantes integradas, lo que explica que en este texto se insista en el despliegue propagandístico y en la urgencia por atraer a un mayor número de concejos que asegurasen el éxito de la hermandad. En el capítulo 33 se establecía una lista de ciudades y villas que era preciso captar para la organización y qué concejos serían los encargados de persuadirlas. La lista muestra tanto los objetivos prioritarios de la institución, es decir, aquellos concejos que se consideraban fundamentales y que potencialmente provocarían una reacción en cadena, ya fuera por arrastrar consigo a otros municipios

${ }^{78}$ Ibidem, p. 351.

${ }^{79}$ Ibidem, pp. 364-365. 
en su jurisdicción o bajo su infuencia, o por el prestigio y fuerza que otorgarían a la hermandad. Por otra parte, la lista emparejaba estos municipios objetivo con otros que, hallándose en la hermandad, se consideraban con mayores opciones para atraer a los primeros, lo que por fuerza debía reflejar el reconocimiento por parte de la hermandad de una relación especial entre los concejos emparejados, basada bien en la influencia o bien en la cercanía e intensidad de intercambios. Así, Toledo y Guadalajara serían requeridos por la villa de Madrid; Segovia por Ávila; Cuenca por la Sagra de Toledo, Pinto, Parla, Limano y Batres; Huete por Casarrubios del Monte, Barajas, Alcobendas, Piedrazuela y San Agustín; el condado de Manzanares por los once sesmos; Burgos por Palencia; Alfaro, Calahorra, Santo Domingo de la Calzada y Logroño por Palenzuela; Oviedo y su principado y Avilés por León; Galicia por Benavente; Villalón y Mayorga por Medina de Ríoseco; Coria, Cáceres y Badajoz por Zamora; la provincia de León dentro del maestrazgo de Santiago por Toro; la provincia de Castilla por el condado de Manzanares; Moya y Requena por Salamanca; y Ciudad Rodrigo por los lugares de Juan de Olloa ${ }^{80}$. Dado que a menudo los concejos que requerían no tenían un estatus mayor que aquel requerido, este acto, el acudir como representantes de la hermandad ofreciendo a otra ciudad, villa o lugar su adhesión a una institución de ese calibre, proveía un cierto prestigio a aquellos que requerían y que acudían respaldados por la autoridad de la hermandad al completo.

Sin duda uno de los escenarios en los que se ponían de manifiesto las redes urbanas preestablecidas entre los distintos municipios era el apellido. Desde sus inicios las hermandades incluyen esta práctica como recurso fundamental para socorrerse unas a otras, sin embargo, la movilización de cuadrilleros y su traslado de unas localidades a otras resultaba muy gravoso para los concejos. Las juntas detectaron que el recurso al apellido ocasionaba mayores gastos de los necesarios porque los municipios no enviaban a llamar a las localidades más cercanas ni movilizaban a una cantidad de personas proporcional al peligro existente o a los efectivos necesarios para perseguir a los malhechores. En la junta de Medina del Campo de 1466 se procura racionalizar el uso de estos recursos estableciendo un protocolo para los apellidos basado en la cercanía. Sin embargo, a finales de año en Fuensalida se hacía necesario insistir nuevamente en el protocolo a seguir. La ciudad, villa o lugar debía requerir a las dos ciudades, villas o lugares más cercanos y cada una mandaría cuatro hombres de buen seso por procuradores que, junto al concejo de la primera localidad, determinarían si era caso de hermandad y si correspondía hacer llamamiento. En dicho caso, acudirían doce alcaldes de hermandad

${ }^{80}$ Ibidem, p. 352. 
de las ciudades, villas, lugares, sexmos, ochavos, cuartos, valles y alfoces más cercanos siempre que algunos fueran de ciudades y villas cercadas. Estos doce alcaldes junto a los ocho diputados iniciales y el concejo del municipio que hubiese hecho el apellido habrían de resolverlo sin hacer más juntamientos de gente ni costas a la hermandad. Finalmente se establecía que nadie de pie de un concejo pudiera ser llamado desde más distancia de siete leguas y, si por la gravedad del hecho se requieriese a toda la gente de la provincia de la localidad o de otra provincia cercana, que aunque fueran provincias diversas se recurriera a las localidades dentro de las siete leguas. Estas medidas prueban que en el recurso al apellido, los criterios de los concejos - que pedían ayuda a las poblaciones que formaban parte de sus redes urbanas-, no siempre coincidían con los de la junta general, basados en un criterio absoluto de cercanía que no consideraba la afinidad y los lazos existentes entre diferentes municipios.

\section{CONCLUSIONES}

Dejando a un lado la discusión metodológica acerca de cuál puede ser el mejor enfoque para medir o analizar la jerarquización urbana en época medieval, este artículo propone una perspectiva complementaria centrada en las propias organizaciones supraurbanas diseñadas por las oligarquías ciudadanas. A lo largo de las páginas precedentes se ha realizado un exhaustivo recorrido por la documentación de las hermandades que muestra cómo en el contexto del establecimiento y negociación de coaliciones urbanas se ponían en juego, se escenificaban y se consolidaban las posiciones de los distintos concejos dentro de una jerarquización que oscilaba entre lo implícito y lo explícito. Esta perspectiva subraya la solidaridad y el reconocimiento mutuo de las propias ciudades, frente a conceptos de jerarquía directamente derivados de la política oficial regia o basados en criterios socio-económicos actuales.

A pesar de las limitaciones de las fuentes del periodo, la documentación hermandina permite reconstruir una serie de tendencias contradictorias entre sí a las que se encuentran sometidas estas organizaciones: en primer lugar, la tensión existente entre las concepciones de tipo igualitario y el reconocimiento de la prelación de ciertos concejos; en segundo lugar, la disonancia entre los intereses de los concejos y redes urbanas de ámbito comarcal o regional y los criterios y objetivos de las juntas centrales; y en tercer lugar, la voluntad de independencia de las hermandades frente a las intromisiones de distintos poderes locales y centrales.

Estas tendencias conectan directamente con dos preguntas fundamentales en el estudio de las ligas urbanas y la jerarquización. En primer 
lugar, en qué medida se corresponden estas ligas con redes urbanas y, en segundo, si las ligas determinan el espacio contribuyendo a la conformación de regiones ${ }^{81}$. A lo largo del artículo se han dado datos en ambas direcciones sin abordar directamente la problemática que requeriría de una extensión mucho mayor. Respecto a la segunda cuestión, el volumen editado por Laurence Buchholzer y Olivier Richard analiza precisamente la relación entre ligas y espacio, llegando a la conclusión de que:

Les ligues produisirent des espaces, mais ils furent des territoires discontinus, peu matérialisés, peut-être incomplets, faute d'un investissement affectif commun des lieux. La forte dimension spatiale et nationale que leur ont prêtée les historiographies contemporaines semble surtout un effet rétrospectif. Au Moyen Âge, le lien social prime sur le spatial ${ }^{82}$.

Tal conclusión parece confirmar que la perspectiva de red urbana se ajusta más a las condiciones del periodo que nuestra concepción actual de región. Sin embargo, tampoco la constatación de estas redes urbanas se antoja sencilla. Jean-Luc Fray señala que para que se trate de una red de ciudades debe existir un flujo entre ellas, es decir que deben mantener una serie de relaciones de intercambio mercantil, de capital y de población, así como alianzas políticas, económicas o matrimoniales ${ }^{83}$. Bajo esta definición este autor considera que la región de la Lorena no fue propiamente una red urbana hasta los años entre 1570 y $1630^{84}$. Por el contrario, Odile Kammerer, en su estudio sobre las ciudades del Oberrhein considera que las redes urbanas son previas a las ligas ${ }^{85}$.

Es evidente que el criterio del flujo entre ciudades -ya sea de materiales, personas o información- resulta un parámetro difícil de mesurar y constatar, especialmente en el caso de las hermandades castellanas del periodo clásico. Aunque faltan datos para poder constatarlo con seguridad, en este artículo se ha sugerido que algunas de las hermandades menores se corresponderían con la existencia de una red urbana, si bien esta red no tendría por qué coincidir de forma estricta con los límites espaciales y temporales de dicha liga. Esta hipótesis concuerda con los resultados expuestos que muestran una funcionalidad limitada por parte de las hermandades generales. Estas se ven lastra-

\footnotetext{
${ }^{81}$ La relación entre ciudad y región ha sido objeto de un reciente trabajo centrado en Burgos en el siglo XV, Sebastián 2017.

${ }^{82}$ Buchholzer, Richard 2012, p. 18.

${ }^{83}$ Fray 2006, p. 444.

${ }^{84}$ Ibidem, p. 468.

${ }^{85}$ Kammerer 2001.
} 
das tanto por la necesidad de llegar a acuerdos generales, como por el traslado de los representantes para realizar juntas conjuntas, que a menudo se muestran como escollos insalvables ${ }^{86}$. Las hermandades menores, con objetivos más concretos, basados en necesidades económicas o defensivas y de pacificación comunes, tienen una mayor longevidad, porque operan sobre redes urbanas más cohesionadas, entre municipios con una mayor densidad de intercambios. Sin embargo, ante las dificultades para analizar dichos flujos entre centros urbanos, parece menos arriesgado mantener la discusión principalmente en términos de jerarquización entre ciudades. El análisis de periodos posteriores mejor documentados podría avanzar resultados más concretos al respecto.

Aunque no ha habido lugar en este artículo para profundizar en las ligas urbanas después de Enrique IV, tanto el proceso de construcción de la Santa Hermandad por parte de los Reyes Católicos en 1476, como la relación entre las hermandades y las Comunidades han sido de sobra estudiadas. El primer fenómeno, por tratarse de una transición orquestada desde la corona resulta menos interesante en lo que se refiere a las dinámicas internas entre las distintas ciudades ${ }^{87}$. Con respecto a las Comunidades, se ha estudiado con mayor prolijidad las similitudes entre hermandades y Comunidades, así como las menciones de términos como el de "hermandad" durante el movimiento comunero ${ }^{88}$. Menos estudiado y con mayor interés para el enfoque aquí propuesto es la serie de intentos que se produjeron antes de 1519 de alianzas o hermanamientos entre distintas ciudades. Autores como María Asenjo o Máximo Diago han señalado los distintos intentos de constituir nuevas alianzas entre ciudades que tuvieron lugar desde $1516^{89}$, y en un artículo de próxima publicación analizo el intento de hermandad con el que Valladolid iniciaba esta tendencia ya en $1506^{90}$. La convocatoria a una serie de ciudades y villas de la Meseta Norte a reunirse en Medina del Campo generó una correspondencia en la que se evidencia el enorme poder propagandístico que dicha iniciativa confería a Valladolid ${ }^{91}$. A través de esta, la villa forzaba el reconocimiento de su preeminencia dentro del sistema urbano de la Meseta Norte y se establecía a sí misma como la primera ciudad en acudir al socorro de la reina y el reino.

\footnotetext{
${ }^{86}$ Las quejas por las dificultades a la hora de superar las distancias entre ciudades aparecen también en las ligas centroeuropeas y serían tanto la expresión de un problema real, como un discurso apropiado para excusar otras motivaciones: Bischoff 2012.

${ }^{87}$ Una excepción notable es el estudio de Guerrero 1986, en el que describe las resistencias de Burgos a renunciar a su papel de líder dentro de la red urbana regional en el momento de la creación de la Santa Hermandad.

${ }^{88}$ Bermejo 1988; Suárez 2007.

${ }^{89}$ Diago 2008; Asenjo 1999.

${ }^{90}$ Martín, en prensa.

${ }^{91}$ AMV, Actas, 1. II, ff. 263-268.
} 
Este estudio ha expuesto las distintas formas en que las hermandades actuaron como síntoma y causa a la vez de la jerarquización urbana en el territorio hispánico hasta 1474. De esta forma, por un lado se confirma que las ligas urbanas constituyeron en Castilla un ámbito privilegiado para el estudio de este fenómeno y, por otro, se sientan las bases para aproximaciones similares a periodos posteriores mejor documentados. Periodos en los que posiblemente las fuentes concejiles permitirán observar aspectos más concretos de las dinámicas de negociación entre las distintas ciudades, así como en qué medida el establecimiento de ligas urbanas abrió el terreno a la negociación de jerarquías entre los concejos.

\section{BIBLIOGRAFÍA CITADA}

Álvarez de Morales, Antonio (1974), Las hermandades, expresión del movimiento comunitario en España, Valladolid, Universidad, Departamento de Historia Medieval.

Álvarez de Morales, Antonio (1985), La evolución de las Hermandades en el siglo XV, en Sáez, Emilio; Segura Graíño, Cristina; Cantera Montenegro, Margarita (coords.), La ciudad hispánica durante los siglos XIII al XVI, Madrid, Universidad Complutense, vol. I, pp. 93-103.

Asenjo González, María (1997), Ciudades y Hermandades en la Corona de Castilla: Aproximación sociopolítica, "Anuario de Estudios Medievales" 27/1, pp. 103-146.

Asenjo González, María (1999), Las ciudades castellanas al inicio del reinado de Carlos V, "Studia historica. Historia moderna" 21, pp. 49-115. Asenjo González, María (2005), Ciudades y poder regio en la Castilla Trastámara (1400-1450), en Foronda, François; Genet, Jean-Philip; Nieto Soria, José Manuel (eds.), Coups d'État à la fin du Moyen Âge?, Madrid, Casa de Velázquez, pp. 365-402.

Asenjo González, María (2008), La colaboración de las ciudades en la estabilidad política del reino (1250-1520), en Nieto Soria, José Manuel; López-Cordón Cortezo, María Victoria (eds.), Gobernar en tiempos de crisis. Las quiebras dinásticas en el ámbito hispánico (12501808), Madrid, Sílex, pp. 175-197.

Asenjo González, María; Crouzet-Pavan, Elisabeth; Zorzi, Andrea (eds.) (en prensa), Urban Hierarchy: the Interaction between Towns and Cities in Europe in Late Medieval and Early Modern Times, Turnhout, Brepols.

Benito Ruano, Eloy (1972), Hermandades en Asturias durante la Edad Media: Discurso de ingreso en el Instituto de Estudios Asturianos, Oviedo, Imprenta La Cruz. 
Bermejo Cabrero, José Luis (1988), Hermandades y Comunidades de Castilla, "Anuario de historia del derecho español" 58, pp. 277412.

Billen, Claire (2013), La construction d'une centralité: Bruxelles dans le duché de Brabant au bas Moyen Âge en Boone, Marc; Howell, Martha (eds.) The power of space in late medieval and early modern Europe: the cities of Italy, Northern France and the Low Countries, Turnhout, Brepols, pp. 183-196.

Bischoff, Georges (2012), Les états unis d'Alsace. Quelques remarques sur la genèse d'un espace politique et sur les pratiques de coopération de ses composantes (XIV ${ }^{e}-X V I I^{e}$ s.), en Buchholzer, Laurence; Richard, Olivier (dirs.), Ligues urbaines et espace à la fin du Moyen Âge / Städtbünde und Raum im Spätmittelalter, Strasbourg, Presses Universitaires de Strasbourg, pp. 121-142.

Borsay, Peter (2004), Urban Network as a Concept in English Urban History, en Gräf, Holger Th.; Keller, Katrin (eds.), Städtelandschaft: Städte im regionalen Kontext in Spätmittelalter und Früher Neuzeit, Colonia, Böhlau Verlag, pp. 1-15.

Buchholzer-Rémy, Laurence (2006), Une ville en ses réseaux: Nuremberg à la fin du Moyen Âge, París, Belin.

Buchholzer, Laurence; Richard, Olivier (dirs.) (2012) Ligues urbaines et espace à la fin du Moyen Âge / Städtbünde und Raum im Spätmittelalter, Estrasburgo, Presses Universitaires de Strasbourg.

Casado Alonso, Hilario (1987) Las relaciones poder real-ciudades en Castilla en la primera mitad del siglo XIV, en Génesis medieval del Estado Moderno: Castilla y Navarra (1250-1370), Valladolid, Ámbito, pp. 193-215.

Christaller, Walter (1966), Central Places in Southern Germany, Englewood Cliffs, Prentice-Hall.

Diago Hernando, Máximo (2008), La cultura contractual en los medios urbanos castellanos a fines de la Edad Media: el resurgimiento de las cortes durante el período pre-comunero, en Foronda François; Carrasco Manchado, Ana Isabel (eds.), El contrato político en la Corona de Castilla: cultura y sociedad políticas entre los siglos X y XVI, Madrid, Dykinson, pp. 453-90.

Escher, Monika; Hirschmann, Frank G. (eds.) (2005), Die urbanen Zentren des hohen und späteren Mittelalters: vergleichende Untersuchungen zu Städten und Städtelandschaften im Westen des Reiches und in Ostfrankreich, Trévens, Kliomedia.

Favier, René (2004), Réseau urbain comme un concept dans l'histoire urbaine en France, en Gräf, Holger Th.; Keller, Katrin (eds.), Städtelands- 
chaft: Städte im regionalen Kontext in Spätmittelalter und Früher Neuzeit, Colonia, Böhlau Verlag, pp. 17-23.

Fray, Jean-Luc (2006), Villes et bourgs de Lorraine. Réseaux urbains et centralité au Moyen Âge, Clermont, Presses Universitaires Blaise-Pascal.

Fuentes Ganzo, Eduardo (2008), Pactismo, Cortes y hermandades en León y Castilla (siglos XIII-XV), en Foronda, François; Carrasco Manchado, Ana Isabel (eds.), El contrato político en la Corona de Castilla: cultura y sociedad politicas entre los siglos X y XVI, Madrid, Dykinson, pp. 415-452.

García de Valdeavellano, Luis (1969), Carta de hermandad entre los concejos de la Extremadura castellana y del arzobispado de Toledo en 1295, "Revista portuguesa de historia" 12, pp 69-74.

García Fernández, Manuel (1985), La Hermandad General de Andalucía durante la minoría de Alfonso XI de Castilla: 1312-1325, "Historia. Instituciones. Documentos" 12, pp. 311-376.

González Mínguez, César (1992), Aproximación al estudio del "movimiento hermandino" en Castilla y León (conclusión), "Medievalismo" 2, pp. 29-60.

González Mínguez, César (2006), Hermandades concejiles y orden público en Castilla y León durante la Edad Media, "Clío \& Crimen" 3, pp. 13-35.

Guerrero Navarrete, Yolanda (1986), La Hermandad de 1476 y Burgos: Un factor decisivo en la transformación del poder municipal a fines de la Edad Media, "Anuario de Estudios Medievales" 16, pp. 533-556.

Häbler, Konrad (1885), Über di älteren Hermandades in Kastilien, "Historische Zeitschrift" 53/3, pp. 385-401.

Häbler, Konrad (1886), Die kastilischen Hermandades zur Zeit Heinrich's IV. (1454-1474), "Historische Zeitschrift" 56/1, pp. 40-50.

Hardy, Duncan (2014), Reichsstädtische Bündnisse im Elsass als Beweise für eine ,verbündende " politische Kultur am Oberrhein (ca. 1350-1500), "Zeitschrift für die Geschichte des Oberrheins" 162, pp. 95-128.

Kammerer, Odile (2001), Entre Vosges et Forêt-Noire: pouvoirs, terroirs et villes de l'Oberrhein, 1250-1350, París, Publications de la Sorbonne.

Martín Romera, María Ángeles (en prensa), Urban Networks "in Defence of the Realm": Castilian Cities in Valladolid's Orbit of Influence from the Hermandades to the Comunidades, en Asenjo González, María; Crouzet-Pavan, Elisabeth; Zorzi, Andrea (eds.) Urban hierarchy: the interaction between towns and cities in Europe in Late Medieval and Early Modern Times, Turnhout, Brepols.

Martínez Díez, Gonzalo (1973), La Hermandad alavesa, “Anuario de Historia del Derecho Español” 43, pp. 5-112. 
Mínguez Fernández, José María (1990), Las hermandades generales de los concejos en la Corona de Castilla: objetivos, estructura interna y contradicciones en sus manifestaciones iniciales, en Concejos y ciudades en la Edad Media hispánica: II Congreso de Estudios Medievales, Madrid, Fundación Sánchez-Albornoz, pp. 537-568.

Paz y Meliá, Antonio (1897), La Santa Real Hermandad vieja y la nueva Hermandad General del Reino, "Revista de Archivos, Museos y Bibliotecas" 3 época I, pp. 97-108.

Pescador del Hoyo, María del Carmen (1971), Los orígenes de la Santa Hermandad, "Cuadernos de Historia de España" 55-56, pp. 400-443.

Prevenier, Walter; Sosson, Jean-Pierre; Boone, Marc (1992), Le réseau urbain en Flandre (XIII ${ }^{e}-X I X^{e}$ siècle): composantes et dynamique, en Le réseau urbain en Belgique dans une perspective historique (13501850). Une approche statistique et dynamique. Actes du quinzième Colloque International de Spa des 4-6 septembre 1990, Bruselas, Crédit Communal, pp. 157-200.

Puyol y Alonso, Julio (1913), Las hermandades de Castilla y León: estudio histórico: seguido de las ordenanzas de Castronuño, Madrid, Imp. de la suc. de M. Minuesa de los Ríos.

Rucquoi, Adeline (1987) Pouvoir royal et oligarchies urbaines d'Alfonso X à Fernando IV de Castille, en Génesis medieval del Estado Moderno: Castilla y Navarra (1250-1370), Valladolid, Ámbito, pp. 173-192.

Ruiz de la Peña, José Ignacio (1978), La Hermandad leonesa de 1313, en León medieval. Doce estudios, León, Colegio Universitario de León, pp. 139-164.

Ruser, Konrad (ed.) (1979-2005), Die Urkunden und Akten der oberdeutschen Städtebünde vom 13. Jahrhundert bis 1549, Göttingen, Vandenhoeck \& Ruprecht.

Sánchez Albornoz, Claudio (1926), Carta de Hermandad entre Plasencia y Escalona, "Anuario de Historia del Derecho Español” 3, pp. 503508.

Sánchez Benito, José María (1987), Santa Hermandad Vieja de Toledo, Talavera y Ciudad Real (Siglos XIII-XV), Toledo, Caja de Ahorro de Toledo.

Sánchez Benito, José María (1990), Colección de documentos de la Santa Hermandad (1300-1500), Toledo, Instituto provincial de investigaciones y estudios toledanos - Diputación provincial de Toledo.

Sánchez Benito, José María (2005), La Hermandad de los Montes de Toledo entre los siglos XIV y XV, "Espacio, Tiempo y Forma. Serie III, Historia Medieval" 18, pp. 209-229. 
Sanz Fuentes, María Josefa (1978), Cartas de hermandad concejil en Andalucía: el caso de Écija, "Historia. Instituciones. Documentos" 5, pp. 403-430.

Sebastián Moreno, Javier (2017) La ciudad medieval como capital regional. Burgos en el siglo XV, Madrid, Universidad Autónoma.

Stabel, Peter (2015), Town and Countryside in Medieval Europe: Beyond the Divide, en Wilkin, Alexis; Naylor, John; Keene, Derek; Bijsterveld, Arnoud-Jan (eds.), Town and Country in Medieval North Western Europe: Dynamic Interactions, Turnhout, Brepols, pp. 313-323.

Suárez Fernández, Luis (1951), Evolución histórica de las Hermandades Castellanas, "Cuadernos de Historia de España" 16, pp. 5-78.

Suárez Varela, Antonio (2007), La conjuración comunera: de la antigua germanitas a la confederación de Tordesillas, "Historia. Instituciones. Documentos" 34, pp. 247-277.

Tilly, Charles (1994), Entanglements of European Cities and States, en Tilly, Charles; Blockmans, Willem Pieter (eds.), Cities and the Rise of States in Europe, a.d. 1000 to 1800, Boulder, Westview Press.

Fecha de recepción del artículo: octubre 2017

Fecha de aceptación y versión final: abril 2018 